\title{
REPERCUSSÕES DO DESENVOLVIMENTO EMOCIONAL INFANTIL AOS PROCESSOS SOCIALIZADORES NA ESCOLA: CONTRIBUIÇÕES À RELAÇÃO PROFESSOR-ALUNO
}

WIEZZEL, Andreia Cristiane ${ }^{1}$

\begin{abstract}
RESUMO: O foco principal deste trabalho reside em caracterizar o desenvolvimento emocional infantil, contrapondo-o aos processos de socialização na escola, cujo ator principal é o professor, por meio da relação que estabelece com os alunos. Aponta as origens e discute as necessidades básicas de desenvolvimento da criança, apontando como os professores podem contribuir neste processo, por meio de um olhar sensível e técnico acerca do comportamento infantil, proporcionado por conhecimentos da teoria de Winnicott. Neste espaço potencial de crescimento que constitui a escola, o papel do professor ao se relacionar e mediar as relações entre as crianças, é um dos fatores determinantes à construções estruturantes acerca de relacionamentos, que estas levarão por toda vida. $\mathrm{O}$ professor, ao conhecer o processo de desenvolvimento emocional de seus alunos e suas formas de expressão, poderá direcioná-los a experiências sociais mais ricas e impactantes à sua formação enquanto pessoa.
\end{abstract}

Palavras-chave: Desenvolvimento emocional. Crianças. Socialização. Relação professor-aluno

SUMMARY: The principal focus of this work is to characterize the children's emotional development, opposing it to the process of socialization in school. Whose the main actor is the teacher, through the relationship with the students. It points out the origins and discuss the basic developmental needs of the child. Pointing out how the teachers can contribute in this process through a sensitive and technical look at child behavior, provided by knowledge of Winnicot's theory. In this potencial space of growth that constitutes the school, the teacher's role to relating and mediating the relationship among the children is one of the determining factors in the structure constructions about relationships that they will carry for life. The teacher, knowing the emotional development process of your students and your way of expressions, can direct them to experiences that are richer and more impactful to their training as a person.

Keywords: Emotional development. Children. Socialization. Teacher- student relationship.

\section{INTRODUÇÃO}

A educação de crianças de 0 à 5 anos traz muitos desafios aos pais e professores. A maior parte destes desafios se relacionam não à questão intelectual, mas, à questões que perpassam o desenvolvimento emocional e, consequentemente, às relações interpessoais que fazem parte do processo de socialização na escola. Tal processo é entendido como um conjunto de momentos de interações entre crianças entre si e com os professores, nos quais há uma assimilação da cultura, dos valores e formas de comportamento socialmente relevantes. Conforme Winnicott $(1982,2005)$, as crianças precisam de tempo e condições ambientais adequadas para que possam se desenvolver livremente, considerando o aspecto emocional. As relações interpessoais que elas estabelecerão em um futuro próximo, serão influenciadas pela fração de desenvolvimento emocional que puderam contar, sobretudo, em seus dois primeiros anos de vida.

Portanto, o professor que trabalha com alunos de até cinco anos, se depara com crianças com experiências e estados emocionais muito distintos, bem como situações de vida e desenvolvimento emocional específicos que não podem ser desconsiderados nos processos de

\footnotetext{
${ }^{1}$ Professor Assistente Doutor do Departamento de Educação da Faculdade de Ciências e Tecnologia, na área de Psicologia da Educação.

UNESP- Universidade Estadual Paulista - Campus de Presidente Prudente/SP
} 
socialização, sobretudo quando envolve conflitos entre as crianças ou entre uma determinada criança e o professor.

Pesquisas como a de Castro (2008) e Winnicott (2005) demonstram que, muitas vezes, os padrões que os professores adotam em suas relações com as crianças pequenas não se aproximam das reais necessidades que as movem em determinados momentos de seu desenvolvimento. Ao que parece a dificuldade dos professores é tanto maior quanto menor é a criança.

Tendo em vista esta problemática a pesquisa tem como foco a relação professor-aluno, de forma a apontar elementos que possam auxiliar o professor a estabelecer padrões de interação mais coesos e relevantes às necessidades de desenvolvimento de cada criança.

Villela e Archangelo (2015) apontam a necessidade de organização da escola neste sentido:

A escola tem de se organizar, buscando o desenvolvimento integral do aluno, seu bemestar [...] a ideia de constituir a escola espaço agradável e favorável a boas relações entre alunos e entre alunos e professores também pode ser considerada uma meta fundamental. É evidente que a escola precisa ter objetivos claros e caminhar nessa direção (VILLELA.; ARCHANGELO, 2015, p. 73).

Os professores necessitam de auxílio nesta trajetória, pois, os cursos de formação inicial ou continuada, pouco ou nada abordam a respeito do tema. Os professores trabalham com pouco referencial, o que os leva a um desgaste físico e emocional, conforme aponta Castro (2000) em pesquisa na qual relata o estado de saúde de professores no manejo diário com crianças que manifestam agressividade.

A aprendizagem bem como o desenvolvimento social envolvem elementos emocionais e estes, na maioria das vezes, são pouco levados em conta. As pesquisas mais atuais na área da educação considerando a natureza e complexidade dos objetos de estudo que a realidade tem colocado - têm utilizado cada vez mais as contribuições de várias áreas do conhecimento às investigações e, a psicanálise winnicottiana, certamente, é uma das fontes mais importantes para se trabalhar com o aspecto emocional na prática pedagógica.

Donald Woods Winnicott, pediatra e psicólogo infantil, trabalhou intensamente no contexto da Segunda Guerra Mundial em instituições que acolhiam crianças órfãs, em decorrência do massacre. Neste contexto teve a oportunidade de estudar não apenas o desenvolvimento emocional - centro de suas investigações - mas as origens de vários distúrbios no comportamento infantil. Concluiu que a criança, sobretudo entre os 0 e 3 anos, necessita de cuidados físicos, apoio, orientação e, sobretudo, relações interpessoais estáveis e de qualidade com adultos (pais/professores) para que possa alcançar um bom desenvolvimento emocional e, consequentemente, esteja apta a se relacionar com as pessoas. Após esta faixa etária, esse conjunto de condições necessita de uma continuidade no tempo, até que o desenvolvimento emocional básico esteja concluído, por volta dos cinco anos.

O objetivo principal deste trabalho consistiu em levantar, por meio da teoria winnicottiana, elementos que contribuam à reflexão acerca da relação professor-aluno, envolvendo crianças de 0 à 5 anos. Esses elementos foram elaborados por meio da relação entre o universo do desenvolvimento emocional infantil, as necessidades afetivas básicas das crianças e de como essas necessidades podem interferir nas características comportamentais em sala de aula.

A pesquisa, de natureza teórica, perpassou seis relevantes obras de Winnicott, nas quais o autor discutiu o desenvolvimento emocional infantil e os comportamentos típicos da infância, difundindo-os ao mundo sob forma de auxílio a pais e professores. As obras foram lidas e fichadas, trabalhando-se com a análise das seguintes categorias: 1- Caracterização do desenvolvimento emocional infantil; 2- Condições necessárias a um bom desenvolvimento emocional; 3-Relação entre desenvolvimento emocional e as 
relações interpessoais e 4- Função do professor no processo de desenvolvimento emocional infantil. As obras de Winnicott utilizadas na pesquisa foram: O brincar e a realidade (1975), A criança e seu mundo (1982), Natureza humana (1990), A família e o desenvolvimento individual (1991), Da pediatria à psicanálise (2000) e Privação e delinquência (2005). Neste artigo serão apresentados os principais resultados obtidos por meio das interpretações do material encontrado.

\section{O DESENVOLVIMENTO EMOCIONAL INFANTIL NA ESCOLA DE EDUCAÇÃO INFANTIL}

O desenvolvimento infantil, considerado em seu todo, envolve vários âmbitos, dentre estes o físico, o psicomotor, o cognitivo, o psicossocial e o emocional. Considerando a concepção das Diretrizes Curriculares Nacionais para a Educação Infantil (2009), o desenvolvimento integral das crianças, envolvendo, portanto, todos os âmbitos há pouco mencionados, constitui objetivo maior desta modalidade de ensino.

Com relação aos âmbitos de desenvolvimento, aquele relacionado ao aspecto emocional é o que mais tem se destacado como desafio à atuação docente. Isto porque este fator pouco é trabalhado nos cursos de formação inicial e continuada de professores e, também, por se constituir aspecto muito abstrato, tendo em conta que envolve processos densos, complexos, não palpáveis diretamente no aluno. Por este motivo, é relevante discutir o aspecto emocional e sua relação com o contexto escolar, para que os professores se familiarizem com o tema e, a partir destas contribuições, possa organizar melhor o seu trabalho.

O desenvolvimento emocional infantil, para Winnicott $(1982,1990)$, está relacionado à formação de uma base emocional segura, representada por um "bom início" de vida à criança. Esse bom início de vida supõe uma mãe ou cuidador "suficientemente bom"- não uma pessoa "perfeita" - que ofereça à criança cuidados físicos e emocionais.

A criança pequena precisa se adaptar ao mundo e, se esta adaptação for realizada com simplicidade, por etapas e de forma atenciosa pelos cuidadores, estar-se-á auxiliando na formação de bases para um saudável desenvolvimento emocional. Essas bases só se estruturam efetivamente na presença de relações interpessoais de qualidade entre a criança e a família e, inicialmente, sobretudo com a pessoa que mais convive com ela ao nascer.

O bebê possui necessidades físicas e emocionais que o tornam, no começo da vida, totalmente dependente dos adultos. Ao longo do desenvolvimento seu "eu" vai se formando e se consolidando, o que o capacita para caminhar rumo à independência. Tal processo envolve um longo caminho, marcado pelo surgimento de sentimentos contraditórios de culpa, de raiva, de amor, de preocupação e reparação, que a criança precisa aprender a suportar e a gerenciar (WINNICOTT, 1992).

Nesta jornada nada será mais importante do que o contato afetivo que o bebê terá com sua família. O mundo será apresentado a ele "em pequenas doses" (WINNICOTT, 1982), de forma que possa incorporar suas experiências com tranquilidade, desenvolvendo-se sob o amparo das "quatro paredes" do lar.

O ambiente precisa ser estável, isto é, proporcionar-lhe cuidados básicos que se adequem às suas necessidades fisiológicas e emocionais. Os "cuidados emocionais" (tais como a atenção, o apreço e o vínculo afetivo), assim como os cuidados físicos, necessitam de uma continuidade no tempo. Se forem interrompidos bruscamente, podem gerar uma intrusão ao desenvolvimento infantil, produzindo uma estagnação ou mesmo perturbações. O bebê, neste caso, tenderá a gastar sua energia vital na produção de mecanismos de defesa contra a intrusão, desviando-se do processo desenvolvimento emocional saudável.

Nucleus,v.16,n.2,out.2019 
O processo principal que a criança vivencia nesta constituição do "eu" envolve a integração da personalidade. Uma vez que o bebê se reconheça como um ser distinto de outras pessoas, terá dado um grande passo. O bebê vive, nesta primeira fase, o processo de ilusão, momento em que alucina a tudo criar e possuir pleno controle sobre suas criações, que são empregadas sempre que tiver alguma necessidade. Uma de suas criações é o seio materno e tudo mais o que puder desejar em momentos de dificuldades.

Gradualmente esta ideia de onipotência vai se perdendo e o bebê adentra um pouquinho mais na realidade objetiva, de forma a ir se acostumando a viver neste lugar, isto é, em nosso mundo. Winnicott (2000) destaca que o bebê começa a perceber, por exemplo, que alguém prepara sua mamadeira e que esta, portanto, não surge magicamente, a partir de seu desejo. Isso é possível porque a mãe ou cuidador inicia o processo denominado desilusionamento, o qual, começa por desenvolver no bebê a capacidade de esperar, de postergar suas necessidades, a partir da experiência da frustração. Portanto, a função materna passa pelo momento de iludir a criança e pelo momento de desilusionamento dela, ainda que a mãe não perceba que o faça.

A criança, inicialmente, precisa de uma boa adaptação dos cuidadores e acreditar que produz e controla tudo que necessita, para que possa ter tranquilidade para seguir ao encontro da realidade. Neste processo, portanto, a adequada ação materna no tempo é muito importante, assim como destaca Winnicott (1975):

Não obstante, de saída, a adaptação [materna] precisa ser quase exata e, a menos que assim seja, não é possível ao bebê começar a desenvolver a capacidade de experimentar uma relação com a realidade externa ou mesmo formar uma concepção dessa realidade (WINNICOTT, 1975, p. 26).

No próximo momento precisará ir perdendo essa condição para que possa enxergar as pessoas, o real, os objetos, indo ao encontro do mundo, assim como preconiza Winnicott $(1992,2000)$. A perda progressiva do controle mágico durante o desilusionamento é importante para que o bebê aprenda a suportar pequenas frustrações, preparando-se para o desmame, cujo encerramento da amamentação é apenas um dos aspectos envolvidos. Winnnicott (1975) em "O brincar e a realidade", deixa claro essa questão:

[a desilusão] é preliminar à tarefa do desmame e também continua sendo uma das missões dos pais e dos educadores [...] se tudo corre bem nesse processo gradativo de desilusão, o palco está pronto para as frustrações que reunimos sob a palavra desmame. O simples término da alimentação ao seio não constitui desmame (WINNICOTT, 1975, p. 28).

Para o autor, a mãe ou o responsável pela criança são, portanto, figuras importantíssimas dentro do processo ilusão-desilusão, incluindo os professores. A criança só se sentirá segura e com o desejo de encontrar o mundo se sentir que este é um lugar que "que vale a pena" (WINNICOTT, 1992). Isso somente é possível se, de forma geral, teve mais experiências boas do que más. Do contrário sentirá medo e insegurança diante desse mundo, que terá percebido como ameaçador.

Posto isso algumas condições ambientais são essencialmente importantes, tais como a estabilidade emocional dos cuidadores, a continuidade dos cuidados físicos e emocionais ao longo do tempo e o conjunto de experiências que o ambiente proporcionará à criança. É relevante apontar que a criança suporta, conforme Winnicott (2005), eventos intrusivos a seu desenvolvimento até um certo ponto, porém, em um aspecto geral, as intrusões não devem prevalecer, já que podem levar ao caos ou a uma não integração do eu.

O que caracterizam as intrusões ao desenvolvimento emocional infantil? As intrusões são caracterizadas por ocorrências que podem ser controladas pelos adultos ou não e que causam uma lacuna 
ou uma paralisação no desenvolvimento da criança. A criança continua crescendo fisicamente, porém, emocionalmente, o desenvolvimento toma um curso não programado, distorcido, que pode levar à consequências de vários níveis.

Para Winnicott (1992) isso ocorre porque ao sofrer uma intrusão a criança passar a reagir a esta e, enquanto isso ocorre, deixa de se desenvolver de forma significativa. Como exemplos de intrusão podem ser considerados: morte/hospitalização de progenitores ou cuidadores, hospitalização da criança, viagem longa dos pais, enfim, qualquer situação em que haja uma interrupção em uma boa relação que o bebê ou a criança vinha estabelecendo com alguém importante em sua vida.

Quando isto ocorre, há um risco de perda de representação da figura da mãe, algo que traz prejuízos ao desenvolvimento emocional, como o próprio autor afirma:

Como se sabe, quando a mãe, ou alguma outra pessoa de quem o bebê depende, está ausente, não há uma modificação imediata, de uma vez que o bebê possui uma lembrança ou uma imagem mental da mãe, ou aquilo que podemos chamar de uma representação interna dela, a qual permanece viva durante certo tempo. Se a mãe ficar longe por um período de tempo além de certo limite medido em minutos, horas ou dias, então a lembrança, ou a representação interna, se esmaece (WINNICOTT, 1975, p. 30).

A partir do momento em que a imagem mental da mãe é perdida, a tendência é que tudo aquilo que estruturava a criança, também seja abalado. Instala-se, nos casos mais graves e, de acordo com a idade do bebê, um sofrimento caracterizado por Winnicott como algo muito profundo e desestruturante, marcado pela quebra de seu porto seguro na caminhada rumo à realidade. Além da intrusão os maus tratos - envolvendo questões físicas e emocionais -, isolamento e uma relação afetiva marcada por frieza excessiva e distanciamento, também prejudicam o desenvolvimento emocional. A necessidade da presença física e afetiva de quem cuida da criança mostra que cuidados impessoais, que ocorram no lar ou na escola, como Winnicott apontou na obra "A criança e seu mundo" (1982), ou a criança ser tratada como se fosse apenas um ser fisiológico, também contribuem ao mal estar infantil.

O caos na integração da personalidade aparece, como já citado em Winnicott (1992), em decorrência das intrusões. A recuperação do estado inicial pode ser obtida por meio da revivência da continuidade do que foi rompido. Na maioria das vezes, alguma alteração no próprio entorno da criança colabora para seu retorno ao desenvolvimento emocional saudável. Isso é possível porque o caos só existe em algum lugar onde já houve ordem, isto é, que já possui certa base ou estrutura (integração). Quando o bebê não chega a atingir a integração a situação é potencialmente mais grave, sendo a separação psique/soma algo preocupante, que pode levar à psicose.

Quanto menor a criança mais atenção e cuidados precisa. A partir do momento em que inicia a independência, ela pode e se abre mais ao mundo, às relações com as outras pessoas, porém, tudo dependerá de como foi o início de sua vida, sobretudo até os dois anos de idade. O crescimento, como afirma Winnicott (1992), é cheio de conflitos e a criança experimenta muito cedo sentimentos intensos e contraditórios, sobretudo em sua relação com os cuidadores. Há que haver um ambiente que sobreviva às suas investidas e testes - indícios de que a criança está entrando em contato e experimentando seus sentimentos, aprendendo a conviver com estes e a controlá-los. A criança só se sente segura para entrar em contato com seus sentimentos se houver um ambiente que a acolha, suporte e a ajude na contenção de seus impulsos, incluindo os destrutivos (agressivos).

A partir do momento em que a vida emocional da criança está mais estruturada, e os sentimentos da criança estejam fluindo de forma mais organizada, estará em condições de expandir seu universo de relações para o convívio na escola, seus desafios e aprendizados. 


\section{O DESENVOLVIMENTO EMOCIONAL INFANTIL E SUAS REPERCUSSÕES À RELAÇÃO PROFESSOR-ALUNO}

Considerando as características do desenvolvimento emocional infantil, há que se considerar que a entrada da criança na escola não prescinde do contínuo investimento no aspecto afetivo. As necessidades básicas da criança continuam sendo as mesmas, por isso a relevância do cuidar e o educar, assim como apontam as Diretrizes Curriculares Nacionais para a Educação Infantil (2010).

Isto supõe que o papel do professor, em certa medida, se assemelha ao papel dos pais no que diz respeito aos cuidados físicos com a criança. Com relação ao aspecto emocional, além de se relacionar com essa criança, o professor precisa trabalhar para auxiliar no desenvolvimento desse aspecto. Nesse sentido seu papel se diferenciará daquele dos pais, pois utilizará de conhecimento técnico de sua profissão e sensibilidade para conduzir sua relação com a criança, de forma a acolhê-la e auxiliar em seu desenvolvimento.

Winnicott (1982) ao discutir o papel do professor aponta que este possui função muito especial, sobretudo quando a criança tem de 0 à 2 anos, fase crítica dentro do processo de desenvolvimento emocional. Na escola o professor pode se deparar, a depender da idade, com bebês que estão em processo de formação e integração do "eu", portanto, conforme Winnicott (1992), precisam de apoio emocional, além das áreas específicas que a escola trabalha.

A ocasião da entrada na escola e o consequente distanciamento, ainda que temporário entre a criança e a mãe, são passíveis de ocasionar dificuldades à primeira, que pode reagir de formas variadas: choro, comportamentos agressivos, apatia, recusa a comer, recusa em realizar as atividades propostas em sala de aula, enurese, dentre outros. Esse caso faz menção clara à desestabilização e ansiedade de separação e, aparentemente, é algo simples, porém, é sofrível à criança já que, dependendo da faixa etária, está mais propensa a temer a perda da mãe e a sofrer as consequências deste processo.

Na obra "Privação e delinquência" (2005), Winnicott relata o caso de crianças que ficaram afastadas dos pais por conta da Segunda Guerra Mundial e que, com o decorrer do tempo, passaram a apresentar altos níveis de hostilidade e agressividade nas instituições. Pesquisas realizadas por ele mesmo, que à época era supervisor de uma dessas instituições, demonstraram que o rompimento dos laços afetivos das crianças com as famílias trouxeram prejuízos ao desenvolvimento emocional, ocasionando lacunas. A partir do momento em que há uma intrusão no desenvolvimento, defesas são produzidas e as crianças podem se comportar de forma a reestabelecer os vínculos que perderam, no caso, chamando a atenção por comportamentos inadequados para que sejam auxiliadas.

Devido à complexidade de sua função, o professor precisa conhecer em profundidade o desenvolvimento emocional infantil, de forma que possa compreender as subjetividades e oferecer aquilo que cada criança necessita. Winnicott (2005) aponta que quanto menor a criança maiores serão as necessidades emocionais, já que se encontra em processo de formação de base estrutural. Daí a importância de atenção no processo de adaptação das crianças no momento em que adentram os muros escolares.

Diante desse contexto como podem ser analisadas as relações que se estabelecem entre professor e aluno? As relações são intensas e marcadas por necessidades infantis que remontam ao lar. A criança buscará no professor algo próximo do que busca ou espera encontrar em casa. O bebê de zero a dois anos, por sua vez, não consegue discernir muito bem os vínculos, as emoções, os contextos, chegando a chamar o professor de "mãe".

Winnicott (1982) aponta que a relação que os pais desenvolverem com o professor terá implicações diretas nos vínculos que a crianças vierem a estabelecer com este profissional. O professor, 
nesta perspectiva, além de se relacionar bem com as crianças precisa considerar a relevância de um bom relacionamento, também, com os pais. Uma família confiante no trabalho do professor, transmitirá segurança à criança e será mais colaborativa e receptiva ao trabalho da escola. Além disso, a troca de informações sobre a criança será muito importante ao seu trabalho, tendo em vista que tudo o que acontece em um espaço poderá se refletir no outro.

Nesse sentido, uma questão que impacta no desenvolvimento emocional da criança relaciona-se à ocorrências que causam mudanças bruscas no lar. Geralmente esse tipo de mudança geralmente não é bem recebida pela criança por colocar em risco a estabilidade ambiental que tanto necessita. Diante disso, pode reagir de várias formas: alteração na atenção, na alimentação e no comportamento em geral, apresentando condutas diferentes das usuais em sala de aula. Da mesma forma as crianças pequenas podem reagir quando da troca inesperada e/ou contínua de professor, já que causa uma interrupção em um vínculo forte. Em pesquisa realizada em salas de aula com crianças que apresentavam muitos comportamentos agressivos Ferreira (2016) constatou, dentre outros aspectos, a frequente troca de professores. O fato trazia instabilidade aos alunos que, a cada momento, precisavam se adaptar a outro profissional. Com o tempo já não tinham mais condições de serem receptivos aos professores novos, podendo estar a evitar os vínculos justamente pelo medo da ruptura/perda. Tal hostilidade diante de professores novos dificulta o desenvolvimento do vínculo e ao professor se torna mais complexo se relacionar com esses alunos.

As mudanças na dinâmica do lar geralmente estão associadas a ocorrências que, assim como já apontado, muitas vezes não podem ser controladas pela família, tais como o nascimento de irmãos, separações, mortes de familiares, morte de animal de estimação, viagens longas dos pais (ausência maior do que a criança consegue suportar), doenças, hospitalização, dentre outros. Tais situações podem redundar em alterações nos padrões de comportamento que a criança apresenta na escola, incluindo maltrato aos colegas e professores, recusa a comer, enurese, comportamentos regressivos, agitação motora, tensão, oscilação de humor. No lar, a criança se torna propensa a pesadelos, sono agitado, recusa em comer, apresenta episódios agressivos, choro, raiva, apatia, desconfiança, nervosismo.

É relevante destacar, ainda conforme Winnicott (1982), que as mudanças de comportamento que as crianças apresentam, em geral, indicam que estão a utilizar os recursos de comunicação e defesa do organismo (sinal de saúde) para externalizarem seu mal estar ou conflito emocional. Portanto, as alterações comportamentais não implicam, necessariamente, doenças, indicam que algo precisa ser investigado e a criança ser apoiada de acordo com sua necessidade e limites de atuação da escola. $\mathrm{O}$ mais importante é que, diante de situações em que realmente a escola ou a família pouco ou nada possam fazer, seja a criança encaminhada a um profissional. Apenas o professor que possui conhecimento quanto ao desenvolvimento emocional infantil e esteja atento às manifestações da criança, em contato efetivo com a família, poderá estar seguro na definição destes limites.

Para além da questão que envolve as mudanças bruscas no lar, há alguns comportamentos da criança na escola, ainda conforme Winnicott $(1982$, 2005), que remetem a um ambiente instável emocionalmente, que tende a produzir relações afetivas inseguras ou ambíguas. Alguns fatos que elucidam o ambiente instável emocionalmente caracterizam-se por doenças psiquiátricas, vícios diversos, enfim, qualquer fato que dificulte seriamente ou mesmo impeça a família de cuidar da criança e que não haja outra pessoa que assuma tal responsabilidade. Também, em um grau bem menos grave, famílias muito permissivas, que tenham dificuldades em mostrar os limites para a criança, não auxiliando-a no gerenciamento de seus impulsos destrutivos, podem prejudicar o desenvolvimento emocional e, consequentemente, as relações interpessoais se tornarem mais complicadas à ela.

Da mesma forma que no lar, na escola a criança depende de certas condições que possa se desenvolver integralmente. O trabalho do professor, como já mencionado, repete, portanto, alguns 
procedimentos realizados pelos pais (alimentação, troca de fraldas), acrescido do trabalho pedagógico, embasado nas várias experiências que as crianças devem passar nessa modalidade de ensino. Ressalta Winnicott (1982) que mesmo nos momentos de troca de fraldas e/ou alimentação, a criança está recebendo estímulos, percebendo que está sendo cuidada, podendo sentir-se acolhida. Os cuidados físicos são tão importantes quanto o trabalho pedagógico, já que os primeiros se traduzem em "cuidados afetivos", isto é, trazem sensação de amparo à criança. $\mathrm{O}$ trabalho com crianças envolve uma atmosfera em que o cuidado e o ensino são partes fundantes da experiência infantil na escola, assim a criação de um ambiente estável emocionalmente e adaptado às necessidades emocionais de cada faixa etária, é fundamental ao desenvolvimento da criança, em todos os sentidos. É comum alguns alunos de cursos de Pedagogia afirmarem que "Não estão estudando para trocar fraldas"; esse fato não diminui a importância de nenhum profissional da área da educação e, sim, mostra o quão ele está adaptado e tem consciência da amplitude de seu trabalho.

Pelo fato de as crianças permanecerem por muito tempo na escola a maior parte dos conflitos emocionais gerados na infância serão expressos neste espaço, acrescidos dos próprios conflitos gerados e inerentes ao aprendizado do convívio na escola. Assim o professor se deparará com crianças que, diante de contrariedades "se jogam ao chão"; crianças com explosões de raiva e desafio; crianças que batem nas outras "com ou sem motivos"; crianças apáticas ou que têm medo de se relacionarem; crianças muito inibidas socialmente, dentre outros. A intervenção do professor, neste contexto, será adaptada a cada necessidade individual, podendo se caracterizar como estímulo, orientação, diálogo, proteção, mediação de conflitos, estabelecimento de "limites" ou contenção.

É desejável que certos aspectos relativos à educação provenham da família, caracterizando as primeiras aprendizagens em habilidades sociais, o que contribuiria muito ao trabalho da escola e à iniciação às relações interpessoais. Porém, isto nem sempre ocorre, restando à escola não apenas o trabalho de reforçar essas habilidades, mas, em alguns casos, trabalhar com estas desde o início, já que os professores precisam de uma certa organização em sala de aula para ser possível a realização de seu trabalho, além do fato do almejado desenvolvimento social dos alunos.

Muitos profissionais da educação tendem a acreditar que, deixando as crianças "se entenderem", diante de conflitos em sala de aula, estarão contribuindo ao seu desenvolvimento social. Isso é válido até certo ponto e em alguns casos, porém, não deve constituir regra. Há casos que exigem uma intervenção, sobretudo nas idades mais críticas. Muitas crianças chegam à escola e facilmente se adaptam, mas uma parte considerável necessita de apoio, orientação sobre formas de conduta e acompanhamento, especialmente nas manifestações agressivas e inibição exagerada, que não atenuam com o tempo. Os sintomas que geralmente estão associados a dificuldades à adaptação escolar são febre, dor na barriga, choro intermitente, a recusa em se alimentar.

O relacionamento da criança na escola, com o professor, para dar conta desses aspectos, deve ser marcado por algumas características que devem ou deveriam estar presentes nos lares, nas relações da criança com os cuidadores: estabilidade emocional do adulto, continuidade no processo de cuidar, acolhimento e contenção. Esse tipo de relação traz à criança, segundo Winnicott (1992), oportunidade de realizar progressos no campo afetivo, se ocorre em momentos e âmbitos adequados.

Por outro lado, dando uma leveza ao processo educativo, o autor aponta, ainda, que criança sadia grita, pula, corre, não gosta que suas brincadeiras sejam interrompidas, é teimosa, curiosa, gosta de testar o ambiente, protesta. Mais difícil do que lidar com essas situações comuns é considerar o caso de crianças que não "sabem" brincar, que não reagem, que são muito apáticas em sala de aula. Nestes casos, pode haver, em tese, motivos para preocupações maiores. Winnicott (1982) aponta que a criança que se expressa, mesmo que por meio de comportamentos agressivos, em oportunidade de externalizar seus 
sentimentos/conflitos emocionais, oferecendo indícios de suas necessidades, ao passo que as apáticas ou inibidas não. Isso tem como consequência perda de oportunidades, de ter contato com os sentimentos, limitando o campo de experiências emocionais e, portanto, de desenvolvimento. Além disso, em razão de "bom comportamento" essas crianças quase não são notadas, permanecendo aprisionadas em seu mundo interno, com medo de se relacionar com o externo.

Aos poucos e a partir do momento em que o professor vai observando e conhecendo cada criança, sua dinâmica de funcionamento, poderá distinguir entre o que é trivial, novo ou preocupante em seu comportamento. Por exemplo: pode o professor compreender que o motivo de a criança levar um ursinho à escola, mesmo sem sua autorização, pode estar relacionado à falta que sente da mãe. Quando não mais necessitar desse apoio emocional, nas palavras de Winnicott (1975) desse "objeto transicional", deixará espontaneamente de levá-lo.

Para Winnicott (1992) as crianças evoluem e recuam em sua "idade emocional", por isso suas necessidades e comportamentos estão em constante modificação. Nesta perspectiva a escola pode considerar que uma criança de três anos é também uma dois e uma de um ano, em alguns momentos ou situações. $\mathrm{O}$ autor exemplifica esta situação, caracterizando situações que os professores podem se deparar neste contexto:

A professora terá também de encarar, no período inicial da criança na escola, uma surpreendente flutuação entre tendências de grande dependência e independência; além e, mesmo nos últimos tempos da idade de frequência da escola maternal, certa confusão entre o que é certo e errado, entre a fantasia e o fato, entre o que é propriedade pessoal e o que pertence a outros (WINNICOTT, 1992, p. 223).

Neste ponto a escola auxilia no fechamento de ciclos do desenvolvimento da criança, trabalhando alguns detalhes. Assim, ao invés de dizer à criança que "ela voltou a ser bebê" - como já presenciou-se instigando as outras crianças da sala de aula a fazerem o mesmo, o professor pode conversar com ela, tentar identificar o que está se passando, quais suas necessidades, auxilia-la e respeitar esse momento de seu desenvolvimento. Para Winnicott (1982) quando uma criança retorna ao estado ou características de um bebê é porque alguma dificuldade da fase atual impediu seu progresso. A regressão, para Winnicott (1992), tem potencial curativo, pois, por meio desta, é possível à criança reformular suas vivências, compreender e reconhecer a sua dependência. Geralmente as crianças desejam muito um irmão, porém, quando isso se concretiza, algo novo e contraditório surge em seu íntimo, inseguranças e dúvidas podem passar a fazer parte de seu cotidiano, se refletindo em seu comportamento na escola. Assim, a criança pode estar revivendo, por meio do recém-nascido, seus próprios aspectos ainda não superados da fase anterior, ainda muito próxima cronologicamente.

Não se trata de atuação terapêutica o que aqui é relatado como parte inerente ao trabalho do professor, mas de colocar em prática seus conhecimentos técnicos acerca do desenvolvimento emocional infantil. A vida da criança é permeada por sentimentos intensos e contraditórios - já que se encontra em fase de desenvolvimento -, de forma que o professor lida diariamente com suas manifestações, não devendo temê-la. Há a necessidade de condições especiais do ambiente para que a criança se adapte e cresça. Tais condições perpassam a compreensão da criança e a ação docente. Isto está sendo apontado, pois, muitas vezes, o professor chega a identificar os motivos que levam as crianças a agirem de determinadas formas, porém, sua ação se encerra ou se limita a esta constatação. Apenas "justificar" o comportamento de uma criança não é suficiente, essa justificativa só terá valor ou será relevante à medida que (re) direcione a ação docente.

Afirma Winnicott (1992) que quando há falha no âmbito familiar, se esta não for muito profunda, 
a escola, por meio das experiências que proporciona, tem condições de minimizar ou até mesmo corrigir as dificuldades da criança. Isto é possível porque a escola pode ser um alento às crianças que vivam em ambientes muito "pesados", carregados de conflitos. A escola possibilita à criança um ambiente menos tenso, em que ela pode ter vivências profundas e estruturantes dentro um seguro e sólido ambiente.

$\mathrm{Na}$ educação infantil não há espaço para padronizações, para procedimentos impessoais. Ainda que pese e seja importante a questão dos conteúdos de áreas de conhecimentos específicas, na maior parte do tempo as atividades serão permeadas por relações e sentimentos. A criança pequena objetiva mais à professora e seus cuidados afetivos do que às demais atividades escolares e esse fato, obviamente, não implica afirmar que a escola deva se centrar no ofício do cuidar. Essa situação vai se invertendo à medida que a criança ganha mais independência e passa a focar mais nas atividades intelectuais e nos colegas, geralmente, ao final da educação infantil e no primeiro ano das séries iniciais.

No caso de crianças com falhas no ambiente familiar, estas demandarão ainda mais do professor. Winnicott (2005) ao se referir a crianças que apresentam agressividade ou tendência antissocial, afirmou que estas vão à escola com objetivos diferentes das demais crianças: elas buscam o apoio, a contenção, o auxílio no controle de sua agressividade, enfim, tudo aquilo que precisam para retomar o desenvolvimento emocional e, por consequência, o desenvolvimento social. As demais crianças, em geral, são mais interessadas nas atividades cognitivas, precisam do professor com relação à afetividade, mas não da mesma forma e exigência das primeiras. De qualquer maneira, todas as crianças sempre necessitarão de intervenção na lida com seus impulsos e, conforme destaca Winnicott (2005), os professores precisam estar preparados.

A educação na escola maternal exige que a professora esteja pronta a exercer restrições e controles sobre aqueles impulsos e desejos instintivos, comuns a todas crianças, que são inaceitáveis em suas próprias comunidades, fornecendo, simultaneamente os instrumentos e oportunidades para o pleno desenvolvimento criador e intelectual da criança (WINNICOTT, 1992, p. 224).

Para Winnicott (1992), portanto, não há uma regra em termos relacionais que funcione em todos os casos. Ressalta que se a gentileza é interessante em uma turma em outra pode não funcionar e que a tolerância e a liberdade em alguns casos podem ser tão prejudicial quanto um clima de severidade; tudo dependerá das características de cada grupo de alunos e, ainda, de características individuais dentro do grupo.

Já com as crianças maiores, entre os 4 e os 5 anos, o trabalho do professor será muito importante enquanto mediador das relações interpessoais. A escola precisa continuar cuidando e trabalhar as relações entre as crianças, de forma que suas experiências, conforme Winnicott (2011), não venham a abalar a confiança que elas possuem no ambiente. $\mathrm{O}$ autor ressalta que as regressões ainda são comuns neste contexto, podendo a criança vir a precisar novamente levar seu ursinho de pelúcia à escola como forma de conforto ou fazer com que um pouco do lar seja trazido à escola. Por isso não é interessante que se retire, já nos primeiros dias de aula, esse objeto da criança, pois este traz certa segurança a ela. Quando não mais precisar do ursinho, a criança logo o substituirá por um brinquedo menor, tais como miniaturas de carros. Agindo dessa forma, o professor estará auxiliando e respeitando o desenvolvimento emocional da criança, ao permitir que esta utilize seus próprios recursos psíquicos no gerenciamento de suas emoções.

Ao oferecer segurança à criança, o professor a livra de intrusões e a protege de impulsos que ainda não consegue dominar, bem como dos efeitos que estes poderiam produzir. Como se oferece segurança às crianças? Oferece a segurança por meio da estabilidade emocional dos cuidadores e pela continuidade no cuidar e educar. 
As crianças, ainda à mercê de seus impulsos, necessitam de alguma supervisão e orientação para que se minimizem situações que coloquem em risco sua integridade física. Precisam, também, ainda conforme Winnicott (2011), de alguém que as oriente e ofereça um suporte às relações interpessoais, materializado em intervenções específicas de resolução de conflitos. As intervenções realizadas pelo professor se torna conteúdo de desenvolvimento social das crianças, à medida que estas aprendem, sobretudo, pela observação do comportamento dos adultos. Progressivamente, irão utilizando seus próprios recursos e argumentos na resolução de conflitos, não obstante sempre haverá algumas que continuarão demandando mais atenção, seja pelas diferenças subjetivas, seja por diferenças mínimas entre as idades.

Após os cinco anos as crianças terão mais condições de se concentrarem e serem receptivas às atividades escolares, já que a intensa relação afetiva com o professor sai de foco. Precisam muito de atividades lúdicas, seja no parque, na brinquedoteca escolar ou sala de aula, como canal para expressão de conflitos emocionais. Quanto mais esses conflitos puderem se manifestar nas brincadeiras, melhores as possibilidades nas relações interpessoais em sala de aula, tendo em vista que o brincar possui função terapêutica e aprimora as relações.

Finalmente, ao adentrarem o período de latência, por volta dos seis ou sete anos, as crianças estarão ainda mais interessadas nas atividades que envolvem a cognição, estando mais dispostas às amizades e mais maduras, portanto, as relações interpessoais estarão mais favorecidas.

\section{CONSIDERAÇÕES FINAIS}

O trabalho com crianças pequenas, pela própria natureza do desenvolvimento infantil, envolve, significativamente, os aspectos emocionais. Durante a exposição apresentou-se brevemente o desenvolvimento emocional infantil, apontando a relevância dos cuidados físicos e emocionais à criança e a necessidade de sua continuidade no tempo, para que as estruturas da base emocional possam se desenvolver adequadamente.

No contexto escolar a demanda infantil se assemelha muito à que apresenta no lar. O professor possui função complementar ao trabalho da família, atuando de forma a cuidar e educar a criança. Essas duas dimensões da educação infantil precisam coexistir na prática dos professores sob pena de se considerar a criança apenas como ser fisiológico, negando-se as necessidades afetivas e sua importância ao desenvolvimento social.

As necessidades de desenvolvimento emocional das crianças, que perpassam e se refletem em seus relacionamentos com o professor e outras crianças na escola, é que orientarão a atuação do professor na vida de cada criança. Desta forma a relação professor-aluno deverá ser marcada pela presença constante de uma pessoa que produza na criança a sensação de estar segura para se desenvolver livremente.

As crianças da educação infantil aprendem muito diante de experiências de mediação nas relações interpessoais, caso não haja muitos conflitos internos para se preocuparem. Observando a atuação do professor diante de desentendimentos e conflitos de interesses, progressivamente, é possível às crianças internalizarem formas de conduta e mesmo de mediação, que poderão ser empregadas na ausência do professor.

A questão das relações interpessoais é central ao processo de ensino e aprendizagem nesta fase, tendo em conta que pode interferir na qualidade do desenvolvimento emocional da criança e na prática pedagógica. Quanto menor a criança mais precisará de apoio e orientação e, o professor, neste contexto, possui papel especial. 


\section{REFERÊNCIAS}

BRASIL. Ministério da Educação. Secretaria de Educação Básica. Diretrizes curriculares nacionais para a educação infantil. Brasília/MEC, 2010.

CASTRO, R. E. Eles cuidam de crianças. Quem cuida deles? O sofrimento psíquico do professor na relação com a criança considerada agressiva. 2008. 227f. Dissertação (Mestrado - Programa de PósGraduação em Psicologia. Área de concentração Psicologia clínica) - Instituto de psicologia da Universidade de São Paulo. EDUCAR. Curitiba: UFPR, 2008.

FERREIRA, L. D. Agressividade infantil no cotidiano escolar: recursos e estratégias para o professor da pré-escola. 2016. 124f. Dissertação (Mestrado - Programa de Pós-Graduação em Docência para a Educação Básica) - Universidade Estadual Paulista/Faculdade de Ciências. Bauru: 2016.

VILLELA, F. C. B.; ARCHANGELO, A. A escola significativa e o aluno diante da atividade. São Paulo: Loyola, 2015.

WINNICOTT, D. W. A criança e o seu mundo. 6. ed. Rio de Janeiro: Livros Técnicos e Científicos, 1982.

WINNICOTT, D. W. Da pediatria à psicanálise. Rio de Janeiro: Imago, 2010.

WINNICOTT, D. W. Privação e delinquência. São Paulo: Martins Fontes, 2005.

WINNICOTT, D. A família e o desenvolvimento individual. 4 ed. São Paulo: Martins Fontes, 2011.

WINNICOTT, D. O brincar e a realidade. Rio de Janeiro: Imago, 1975.

WINNICOTT, D. Natureza humana. Rio de Janeiro: Imago, 1992. 